\title{
Management of the national economy productivity: the experience of European integration
}

\author{
Lesia Petkova $^{1}$, Olena Berezina, $^{2, *}$, Iryna Honcharenko $^{2}$, Lesya Berezhna $^{2}$, and Dariia Marushchak $^{1}$ \\ ${ }^{1}$ Cherkasy State Technological University, International Economic \& Business Department, 460 Schevchenko Blvd., Cherkasy, 18006 , \\ Ukraine \\ ${ }^{2}$ Cherkasy State Technological University, Finance Department, 460 Schevchenko Blvd., Cherkasy, 18006, Ukraine
}

\begin{abstract}
Productivity and economic growth are key factors to maintain and improve the competitiveness of nations in the global market. The paper analyzes the impact of changes in labour productivity and its effect on the nation's global competitiveness. The research focuses on the European Union countries and Ukraine that experienced the most severe crisis and afterwards the most rapid recovery in the post-crisis period. At the national level, sufficient productivity dynamics are supported by high levels of market competition, broad investment opportunities, and investment promotion. At the same time, the constant acceleration of the action and volatility of exogenous factors of economic development, qualitative transformations of endogenous factors determine the relevance of constant monitoring of the state of productivity and forecasting it for the medium and long-term periods.
\end{abstract}

\section{Introduction}

The key problem of the economy in recent decades has shifted from a lack of natural development resources to a lack of knowledge to further human empowerment. In productivity theories, there is increased attention to the problem of knowledge as the basis for economic growth and productivity improvement, namely, the creation of knowledge, its transfer, and perception, Charles I. Jones, Paul M. Romer [1], Roberto Cardarelli, Lusine Lusinyan [2], Ulrich Kohli [3], Kirk Hamilton, Esther Naikal, Glenn-Marie Lange [4], J. Remes, J. Manyika, J. Bughin [5], Jungsuk Kim \& Jungsoo Park [6], A. Kaasa [7] et al.

The reduction of productivity growth rates in the group of developed countries from $2.4 \%$ in 2000-2004 to $0.5 \%$ in 2010-2014 became a significant problem and actualized the scientific task of searching for new factors of economic growth [8]. The study found that at the turn of the first-second decade of this century, the information and communication technologies gradually lost their reinforcing impulses; the restructuring of domestic operations and global supply chains were completed. The consequences of the global financial and economic crisis had a significant negative impact on productivity dynamics. This was manifested in the growth of negative expectations, reduction of financial and investment flows. Finally, the promising trend of digitalization of the economy at this stage has not yet produced a significant positive effect but has increased the transition costs.

\section{Related literature}

Development within the framework of the integration association contributes to the productivity increase of national economies, attracting the latest innovative growth factors to the fast action. The study of the experience of such growth of the Member States of the European Union is useful for Ukraine and can be carried out by modelling economic development and productivity on the example of the Czech Republic, Hungary, Estonia, Lithuania, Latvia, Poland and Slovakia as the most effective, compared with Ukraine. In this case, we propose to use the algorithm shown in Fig. 1, using the correlation-regression and cluster analyses. The neoclassical approach in the study and forecasting of economic growth and productivity ([1-7] etc.) is based on the production function, the components of which are capital, labour, the total productivity of production factors, etc. depending on the assumptions made about the type of the production function.

The most common methods of productivity assessing determine the amount of GDP created per hour of working time; the volume of output per unit of productive capital; the definition of multifactor productivity, which measures the contribution to the economic growth of other factors that are technological, organizational, and innovative.

The problem of the interdependence of competitiveness and productivity of national economies has been sufficiently studied in the scientific literature. It has been established that the support of competitiveness at the level of national policy contributes to the increase of aggregate productivity and determines the prospects for economic growth. To increase productivity at the micro level the business maximizes its efficiency through the introduction of an innovative product, management technologies, the creation of new products to meet

\footnotetext{
* Corresponding author: o.berezina@chdtu.edu.ua
} 
consumer demand.

Charles I. Jones and Paul M. Romer [1] founded that the contemporary model of economic growth and productivity was determined by four basic components, ideas, institutions, population, and human capital, while the leading role gave to the human capital. Similar conclusions made by Ulrich Kohli [3]: based on the example of the US economy, scientist founded that the modern dynamics of TFP is mainly explained by labour. In the research of US TFP Dynamics made by Roberto Cardarelli and Lusine Lusinyan [2] suggested that policies that promote investment in human capital and innovation may boost aggregate TFP growth.

Kirk Hamilton, Esther Naikal, and Glenn-Marie Lange [4] in the research of productivity growth factors in developing countries, shown the loss of natural resource efficiency and the growing role of innovation and human capital.

Jungsuk Kim and Jungsoo Park [6] grounded that the value of the technological component of productivity growth is growing in the transition process from the middle to high levels of development. This component is critically important in overcoming the challenges that middle-income countries face when they need to transition to a high-income group.
The results of A. Kaasa [7] study proved that a safe and stable environment where people and firms trust institutions, feel secure and participate in social processes is hugely significant for high productivity. In an intersectoral endogenous innovation model, T. Harada [8] proved the crucial role of the relation-specific investment for the evolution of the industry structure. The scientist grounded that productivity growth will be driven by economic policy measures.

J. Lopez-Rodriguez and D. Martinez-Lopez [9] studied non-R\&D innovation activities account and grounded the significant proportion of innovation efforts carried out across very heterogeneous economies in Europe. An extended macro-theoretical growth model allows taking into account these non-standard factors.

The analysis of structural transformations of the Ukrainian economy is carried out in a scientific report "Structural Transformations in the Ukrainian Economy: Dynamics, Contradictions and Impact on Economic Development" (2015) [10]. The results allow substantiating the necessity to deal with technological, institutional, reproductive constraints for accelerating the impact of the latest drivers of productivity growth.

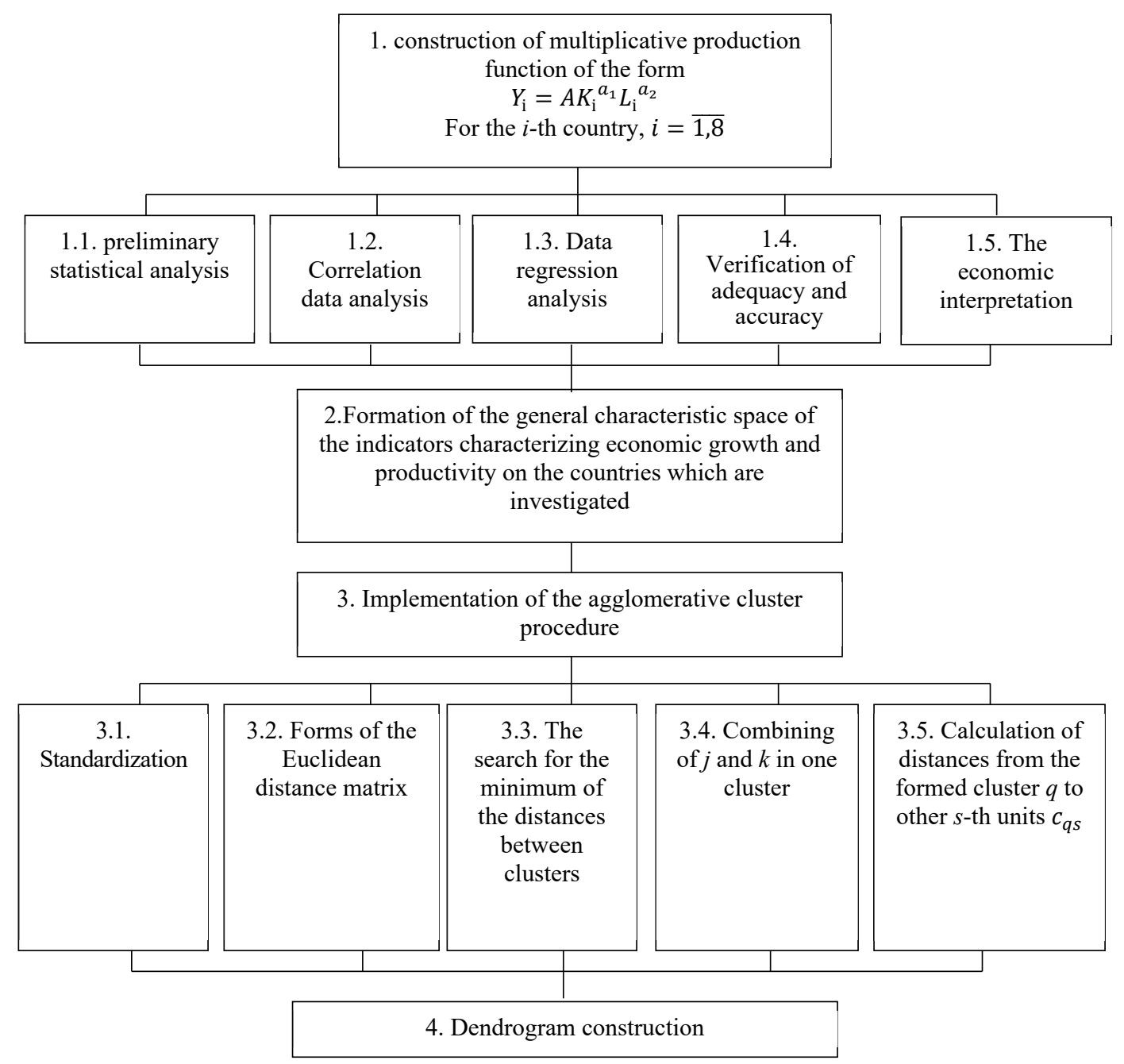

Fig. 1. Procedure for economic development modelling and productivity of countries. 
A. Filipenko [11] noted that the Ukrainian economy characterized by immaturity of the institutional structure, so indirect factors of productivity are also important for it. These factors are the support of civil liberties, participation in civil affairs, support of the interpersonal trust.

Recently, the works $[1-14 ; 16-17]$ discuss the issues of justification of productivity indicators in the economy as a whole and by types of the economic activity based on the multifactor productivity model KLEMS, which combines indicators of the type "capital $(K)$, labour $(L)-$ energy $(E)$ - materials $(M)$ - services $(S)$ ".

Since the early 2000s, the EU-KLEMS consortium has been established in the EU to implement this model. Its main task is to create a database of comparable statistical indicators at the industry level and to conduct a series of studies on the relationship between the growth of labour force skills, technological progress, and innovation, on the one hand, and productivity, on the other. The database contains relevant indicators at the level of 63 industries of the EU Member States, as well as the United States, Japan and Canada and several countries in Asia and Latin America. According to N. V. Stativka [13], the EUKLEMS project investigates the period of 1970-1990. So, scientists from other countries face such disputable issues: 1) lack of access to the information of the created database;

2) other sources of official statistical information do not provide full or partial data on productivity factors for different countries in the retrospective period;

3) partial absence of harmonized indicators of different countries, which are not included in the KLEMS databases, for generalization and international comparisons.

\section{The purpose of the research}

This work aims to analyse the impact of changes in labour productivity and its effect on the nation's global competitiveness based on the experience of EU Central European countries and Ukraine.

The key task for improving resource efficiency as well as the quality of human social capital and the institutional environment is enhancing the productivity of the economy. The productivity's estimating through the TFP model allows assessing the contribution of key factors labour and capital to the national wealth. Ukraine needs a balanced and constructive policy of productivityimproving on the reform pathways. Ukraine has made significant progress in opening up the economy, participating in global trade, manufacturing, and investment processes since 1991. However, the results of the openness policy didn't reflect in the improvement of living standards. Hence, it is important to explore the successful reform experience in European countries that have become EU members and have steadily increased productivity. This will help to identify directions for improving Ukraine's government policy to enhance its international competitiveness.

\section{Results}

The highest levels of socio-economic development are found in the countries with open economies and they actively compete in the world economic space. The international competitiveness of national economies depends on their productivity.

Productivity is usually defined as the ratio between the number of resources involved and the total result. That is, the efficient use of development resources is being under discussion. Long-term trends in productivity give a fairly accurate picture of the prospects for the economic growth of countries, changes in the situation in the industry markets, etc.

To study the indicators of economic growth and productivity of 7 countries that since 2004 have become members of the EU (Czech Republic, Estonia, Latvia, Lithuania, Poland, Slovakia, Hungary) and Ukraine as an information base of the study for 1991-2017, the following statistics [15] were used:

1. GDP (constant prices 2010, USD) - $Y$;

2. Gross fixed capital formation at constant prices in 2010, USD (GDP (constant 2010, USD)) - K;

3 . Employed persons in thousands $-L$;

The whole data set was divided into 2 periods:

1.1991-2003, that is, the period before the entrance of the 7 studied countries to the EU;

2.2004-2017 - the period during which it is possible to allocate consequences for economic development and productivity of these 7 countries after their entrance to the EU and Ukraine, table 1.

The results of the calculations made it possible to form a significant body of information, summarizing which we can draw the following conclusions:

The period of 1991-2003. Only Latvia has an extensive type of GDP growth, with its GDP growing faster than it does on the average with capital and labour. All other countries are characterized by the intensive growth in production, which also increases more slowly than the model factors.

The period of 2003-2017. After the entry of 7 countries under the research into the EU, there was a significant change in the features of GDP growth. In particular, 5 countries (Czech Republic, Estonia, Hungary and Slovakia, and Ukraine) are characterized by an extensive (Fund-intensive) growth in output, and in 3 of these countries, the GDP growth is faster than the average growth of capital and labour. These countries include the Czech Republic, Hungary, and Slovakia. It should be noted that the constructed multiplicative model of the production function for Latvia gave statistically insignificant characteristics and was inadequate. Therefore, it was not included in the overall analysis of productivity and economic development of countries in the study period from 2004 to 2017, and therefore, there is no possibility to compare changes in Latvia before and after the entrance to the EU.

As has been noted earlier, the simulation results allowed us to form a feature space, which can be summarized in the table 1. It should be noted that the economic development of the studied countries is characterized by a significant number of indicators, which 
can include the average growth rates of GDP, gross fixed capital formation, number of employed persons, as well as the results obtained by constructing a multiplicative production function (Fig. 1). The main ones are the coefficient of determination, the average return on capital, the marginal productivity of the main capital, as well as the private elasticity of output by capital and labour.

Table 1. Generalized indicators of economic development and productivity of countries for 2 periods (according to the Eurostat data [15]).

\begin{tabular}{|c|c|c|c|c|c|c|c|c|c|c|c|c|c|c|c|c|}
\hline \multirow{2}{*}{\begin{tabular}{|c|} 
Countries \\
Period $(1-1991-2003,2-$ \\
2003-2017) / Indicators \\
\end{tabular}} & \multicolumn{2}{|c|}{$\begin{array}{c}\text { Czech } \\
\text { Republic }\end{array}$} & \multicolumn{2}{|c|}{ Estonia } & \multicolumn{2}{|c|}{ Hungary } & \multicolumn{2}{|c|}{ Latvia } & \multicolumn{2}{|c|}{ Lithuania } & \multicolumn{2}{|c|}{ Poland } & \multicolumn{2}{|c|}{\begin{tabular}{|c|} 
Slovak \\
Republic \\
(Slovakia)
\end{tabular}} & \multicolumn{2}{|c|}{ Ukraine } \\
\hline & 1 & 2 & 1 & 2 & 1 & 2 & 1 & 2 & 1 & 2 & 1 & 2 & 1 & 2 & 1 & 2 \\
\hline The average GDP growth rate & 2.13 & 61 & .28 & 2.47 & .31 & 1.46 & 5.96 & & .88 & 2.96 & 4.29 & 3.83 & 4.07 & 3.82 & -4.22 & 0.07 \\
\hline $\begin{array}{l}\text { The average growth rate of } \\
\text { gross fixed capital formation }\end{array}$ & 5.58 & 2.29 & 4.13 & 1.88 & 4.69 & 1.06 & 15.99 & - & 11.02 & 3 & 6.3 & 4.99 & 2.07 & 2.93 & -9.01 & -1.64 \\
\hline $\begin{array}{l}\text { The average growth rate of } \\
\text { employed persons }\end{array}$ & -0.2 & 0.76 & .66 & 0.53 & -1.04 & 0.57 & 6.5 & - & -0.49 & -0.31 & -0.39 & 1.3 & $\mid-0.36$ & 1.06 & -1.77 & -1.68 \\
\hline Coefficient of determination & 0.97 & .91 & 0.97 & 0.51 & 0.96 & 0.72 & 0.91 & & 9.92 & \begin{tabular}{|l|}
0.83 \\
\end{tabular} & \begin{tabular}{|l|}
0.99 \\
\end{tabular} & 0.87 & \begin{tabular}{|l|}
0.87 \\
\end{tabular} & \begin{tabular}{|l|}
0.88 \\
\end{tabular} & 0.98 & 0.58 \\
\hline $\begin{array}{|lll|}\begin{array}{l}\text { The average return on } \\
\text { investment }\end{array} & \\
\end{array}$ & 3.91 & 3.73 & 4.7 & 3.71 & 4.96 & 4.63 & 5.58 & 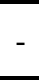 & 5.98 & 5 & 5.9 & 4.97 & 3.56 & 4.27 & 4.07 & 4.94 \\
\hline $\begin{array}{l}\text { The marginal productivity of } \\
\text { fixed capital }\end{array}$ & 1.32 & 0.49 & 2.11 & 0.79 & 2.39 & 0.16 & 1.98 & & 2.75 & 3.33 & 3.32 & 3.68 & 2.08 & 0.41 & 1.97 & 0.44 \\
\hline \begin{tabular}{|l|l|}
$\begin{array}{l}\text { Private equity elasticity of } \\
\text { issue }\end{array}$ \\
\end{tabular} & 0.34 & 0.13 & 0.45 & 0.21 & 0.48 & 0.03 & 0.35 & - & 0.46 & 0.67 & 0.56 & 0.74 & 2.08 & 0.1 & 0.49 & 0.09 \\
\hline $\begin{array}{ll}\begin{array}{l}\text { Private equity elasticity of } \\
\text { issue }\end{array} \\
\end{array}$ & -1.42 & 2.83 & -0.58 & 0.69 & 0.3 & 1.04 & 0.7 & - & -0.88 & -1.33 & -1.97 & -0.13 & $|-3.53|$ & 3.37 & 0.12 & 0.35 \\
\hline
\end{tabular}

It should be noted that the dynamics of productivity in recent years show that entrepreneurs risk losing competitiveness in the EU market. That's why the performance issues are more relevant than ever. Low productivity is a sign that the economic system is unable to allocate resources to produce high-value-added goods.

The analysis of shifts in the share of productivity growth shows that the productivity increase in the sector largely explains the overall development of labour productivity. However, the productivity gains due to the movement of labour from less productive to more productive sectors (the so-called "change effect"). The process of the efficient allocation of resources is a sign of a weak institutional environment. Therefore, it is important not only to promote innovation (in particular, FinTech development) but also to improve the efficiency of market resource mechanisms, minimizing costs and risks. This will increase the competitiveness of production and competitive advantage to attract more investment, especially in the context of the green economy development, one of the major axioms of which is the inability to infinitely expand the sphere of influence in a confined space, and the inability to demand endlessly growing needs in resource constraints.

As can be seen from tablel these indicators are multidimensional and multifaceted, characterized by a significant variation and do not provide an opportunity to fully generalize, evaluate and highlight the similarities of the countries that have become EU members since 2004 or highlight the peculiarity of their economic development and productivity.

This problem can be overcome by applying multidimensional economic and mathematical modelling, in particular, hierarchical cluster analysis. As a result, among the totality of indicators, a class of homogeneous units of the population was formed, a corresponding communication model was constructed and dendrograms were formed using hierarchical clustering procedures, which reflect the measure of similarity of countries in 1991-2003 (Fig. 2) and 2004-2017 (Fig. 3). As is seen in Fig. 2 the graph identifies three clusters that unite two countries. This means that each of these pairs of countries for the period $1991-2003$ had similar values of economic growth. Thus, the Euclidean distance $(E D)$ between Lithuania and Poland was only 1.12, between Hungary and Estonia-1.5, between Latvia and Slovakia - 4.78. The Czech Republic and Ukraine are apart from these countries. However, their Euclidean distances, which characterize deviations in economic development and productivity, are insignificant and practically do not differ from the existing clusters: from $E D=2.49$ (for the Czech Republic) to $E D=4.19$ (for Ukraine). The analysis of the dendrogram in Fig. 2 showed certain changes in the macroeconomic indicators of the studied countries in the multidimensional space for the period 2004-2017, that is, after the entrance of countries (except Ukraine) to the EU. Thus, the graph clearly shows two clusters: the first unites the Czech Republic, Estonia, Hungary, and Ukraine; second-Lithuania, Poland and Slovakia. However, even within a single cluster, the Euclidean distance between countries has a significant variation. Thus, for the first cluster, where the Czech Republic and Estonia were the most related to each other $(E D=4.86)$, the distance to Hungary and Ukraine was as much as 16.14 and 20.51, respectively. According to the second cluster, the indicators of economic development and productivity are the most similar in Lithuania and Poland $(E D=29.93)$. The analysis makes it possible to conclude the relative homogeneity of the indicators of the studied multidimensional space of the economic growth and 
productivity of seven countries after their entrance to the European Union and a certain approximation of Ukraine to them. It should be noted that in Fig. 2. Latvia, for which the model of multiple regression of the labour and capital impact on GDP for the period 2004-2017 was built, appeared inadequate. Therefore, it is impossible to assess the changes in macroeconomic indicators of this country in the multidimensional space after joining the EU in comparison with other countries under the study.

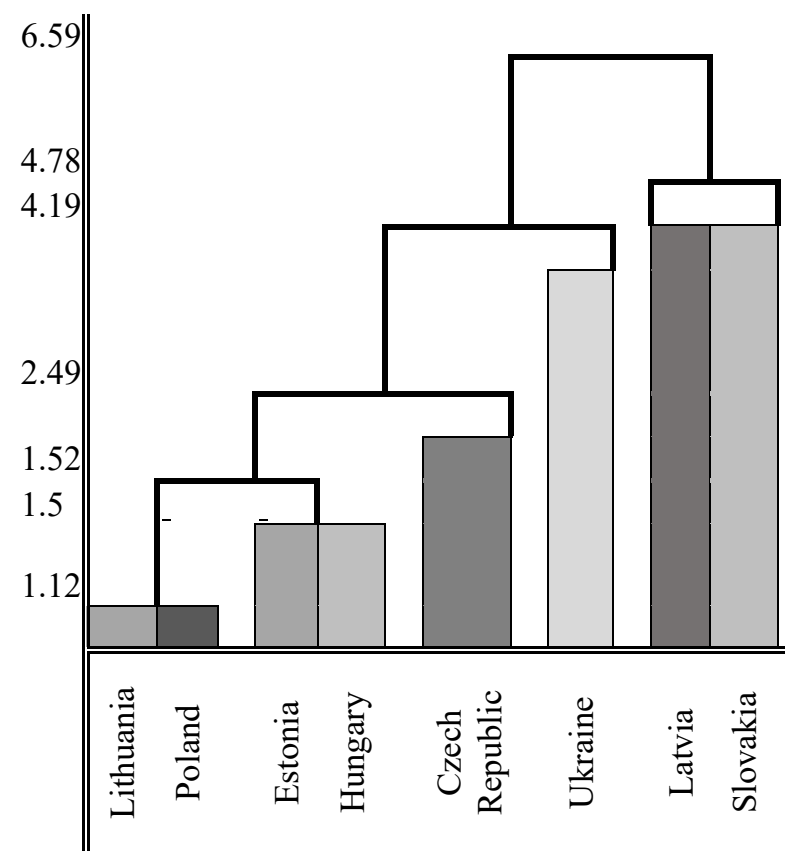

Fig. 2. Dendrogram of clusters (1991-2003).

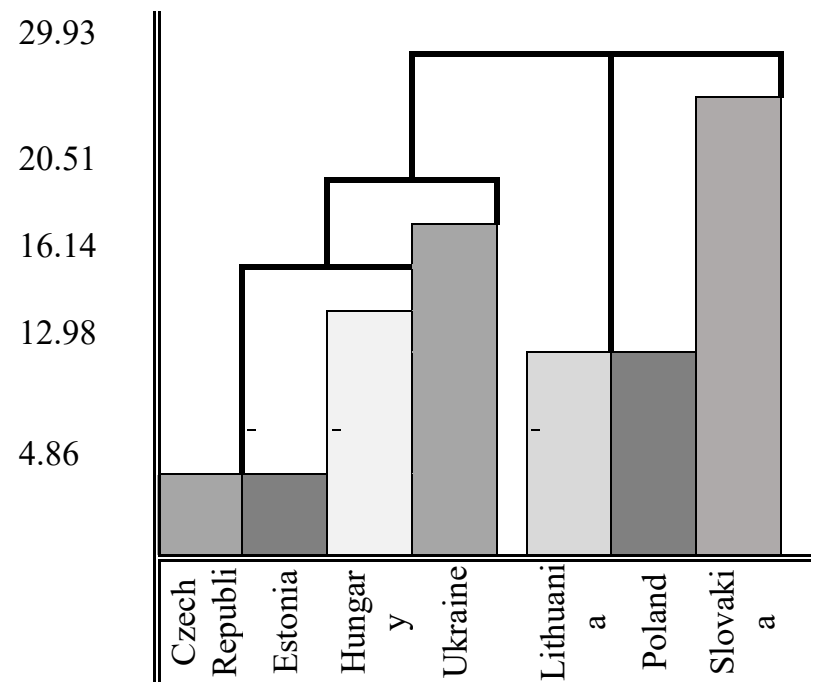

Fig. 3. Dendrogram of clusters (2004-2017).

Paying tribute to the two-factor multiplicative production function (Fig. 1), with the help of which a meaningful analysis of the economic development and productivity of countries was carried out, and despite the rather serious advantages of its application, namely nonlinearity, dynamism, and simplicity, we should not forget about a number of its shortcomings. They include:

- the problem of the scale effect that cannot adequately represent the production process [16];
- the problem of establishing the parameters of the production function-indicators of elasticity of output by resources. Marginal prices of production factors are equal to average prices, which are calculated based on market prices, which is possible only in conditions of market equilibrium and perfect competition [16];

- ignoring the factor of complementarity - the neglect of capital structure in the production function [17].

After all, by [17] the decomposition of capital can be carried out behind such types of assets: the capital not related to the information technology $\left(K_{n}\right)$, hardware $\left(K_{c}\right)$, software $\left(K_{s}\right)$, and telecommunications $\left(K_{t}\right)$ :

$$
Y=A X\left(K_{n}, K_{c}, K_{s}, K_{t}, L\right)
$$

Therefore, further studies must pay special attention and include the components of the capital of information and communication technologies in the set of factors of the model, especially considering the development of FinTech under the conditions of the digital economy.

It should be noted that changes in GDP are not always explained solely by changes in the volume of labour and capital, so it is necessary to carry out modelling of multifactor productivity (Total Factor Productivity (TFP)), which reflects the combined impact of many factors, such as changes in technology and, accordingly, in the professional skills of the workforce, changes in the use of resources, changes in energy prices, economy of the scale, research and development costs.

Another group of issues that need to be addressed in future research is:

1. The weakness of the information base. This reduces the reliability of conclusions and analysis in general. Short time series and poor quality of the initial data (and often their lack of representation in the time interval) make it difficult to obtain reliable econometric estimates;

2. The rapid changes and periods of acceleration and decline in Ukraine, in contrast to the steadily developing market economies where the pace of change is not high. That is, the market system in each subsequent period does not differ much from the previous moment, and the existing differences are considered by introducing minor amendments. Periods of intensification of processes in the crisis economy of Ukraine lead to a loss of comparability between neighbouring points of time series, which creates additional difficulties in the use of econometric methods.

All these problems lead to a focus on improving the quality of models through a thorough approach to the initial data, their preliminary analysis, harmonization, normalization, standardization, and forecasting.

\section{Conclusions and suggestions}

One of the main problems for Ukraine is the creation of new competitive advantages associated with investments in the latest technologies, innovations, research, human capital, efficient allocation of resources and redistribution, which is accompanied by changes in the behaviour of economic entities. Increasing the motivation of entrepreneurs is a major structural change in policy development. The process of structural economic transformation largely depends on the quality of the 
institutional framework (legislation, state aid, and economic and political institutions), which ensures the efficiency of the market of goods and resources, minimizing the costs and risks of the redistribution process, thereby strengthening the competitive advantages of the country.

The research results of the Eastern European countries experience reflected the importance of the institutional environment for successful economic change. Accession to the European legal, economic, technological space contributes to the formation of the necessary quality of institutions in the new countries, which contributes to their productivity. Implementation of all terms set out in the EU-Ukraine Association Agreement has huge importance for Ukraine. The priority is to continue the policy of approximation of Ukrainian legislation system to the EU countries' system.

The main recommendation for government policy to increase the investment attractiveness of the Ukrainian economy are: to promote the diversification of human capital with the strengthening of its intellectual component; to support the conditions of innovative development of Ukrainian business to strengthen the technological level following global trends; to strengthen structural policies with a focus on the green economy by facilitating investments in environmental and environmental technologies, production of environmentally friendly products In order,;

The challenges of increasing national economic productivity are quite acute for Ukraine. Decades of transformational development have not formed a consistent trend of improving the quality of economic growth factors and long-term prerequisites for productivity gains. Therefore, improving the productivity of the national economy will be facilitated by improving the quality of traditional economic factors - labour and capital. Trends in the current development of transformational countries as well as countries with the emerging markets confirm the feasibility of intensifying non-economic factors. The most important of these factors are the characteristics of social capital, in particular, the institutional trust in society and civic engagement.

\section{References}

1. Ch. I. Jones, P. M. Romer, in NBER: Working Paper 15094, National Bureau of Economic Research, Cambridge, June 2009, https://www.nber.org/papers /w15094.pdf. Accessed 10 Jan 2020

2. R. Cardarelli, L. Lusinyan, in IMF WP/15/116 (2015), https://www.imf.org/en/Publications/WP/Iss ues/2016/12/31/U-S-Total-Factor-Productivity-

Slowdown-Evidence-from-the-U-S-42967. Accessed 10 Jan 2020

3. U. Kohli, Explaining total factor productivity (Uni of Geneva, 2015), https://www.business.unsw.edu.au/ About-Site/Schools-Site/EconomicsSite/Documents/Explaining-Total-FactorProductivity.pdf. Accessed 10 Jan 2020
4. K. Hamilton, E. Naikal, G-M. Lange, Natural resources and total factor productivity growth in developing countries: testing a new methodology (2019), http://documents.worldbank.org/curated/en/ 565561547645473522/pdf/WPS8704.pdf. Accessed 3 Jan 2020

5. J. Remes, et al., Solving the productivity puzzle: the role of demand and the promise of digitization (2018) https://www.mckinsey.com/global-themes/meetingsocietys-expectations/solving-the-productivitypuzzle. Accessed 15 Jan 2020

6. J. Kim, J. Park, in ADB Economics Working Paper Series, 527, November 2017, https://www.adb.org/sites/default/files/publication/3 83176/ewp-527.pdf. Accessed 3 Jan 2020

7. A. Kaasa, Econ. and Soc. 9(4), 11-26 (2016)

8. T. Harada, Struct. Ch. and Econ. Dyn. 32, 1-10 (2015). doi:10.1016/j.strueco.2014.12.002

9. J. Lopez-Rodriguez, D. Martinez-Lopez, Struct. Change and Econ. Dyn. 40, 37-45 (2016). doi:10.1016/j.strueco.2016.11.002

10. L.V. Shinkaruk, I.A. Bevz, I.V. Baranovskaya, Strukturni transformatsii $v$ ekonomitsi Ukrainy: dynamika, superechnosti ta vplyv na ekonomichnyi rozvytok (Structural transformations in the Ukrainian economy: dynamics, contradictions and impact on economic development). (NAS of Ukraine, Kyiv, 2015)

11. A.S. Filipenko, J. Int. Rel. S. Econ. Sc. 14, 14-18 (2018)

12. V. Besedin, J. Berd. Uni Men. Bus. 1(33), 16-22 (2016)

13. N.V. Stativka, J. Th. \& Pr. of St. Gov. 4(27), 1-11 (2009)

14. L. Petkova, I. Honcharenko, O. Berezina, M. Leschenko, in Proceedings of the 34rd IBIMA Conference "Vision 2025: Education Excellence and Management of Innovations through Sustainable Economic Competitive Advantage”, Madrid, 2019, ed. by K. S. Soliman

15. Eurostat Database (EU, 2020), https://ec.europa.eu/eurostat. Accessed 15 Jan 2020

16. O.M. Vilchynska, Yu.M. Panochyshyn, T.O. Kushnir, Visnyk of KhNU 2(1), 177-181 (2016)

17. A.O. Kasych, Sc. Is. Econ. Sc. Ser. 21, 28-33 (2013) 